\title{
Reabilitação visual com lentes de contato após trauma ocular
}

\author{
Visual rehabilitation with contact lenses after ocular trauma
}

\author{
Adamo Lui Netto ${ }^{1}$ \\ Aline Cristina Fioravanti Lui ${ }^{2}$ \\ Giovana Arlene Fioravanti Lui ${ }^{3}$
}

Trabalho realizado no Departamento de Oftalmologia da Faculdade de Ciências Médicas da Santa Casa de São Paulo.

${ }^{1}$ Doutor, Professor Assistente da Faculdade de Ciências Médicas da Santa Casa de São Paulo - FCMSCSP - São Paulo (SP) - Brasil.

${ }^{2}$ Estagiária do Departamento de Oftalmologia da FCMSCSP - São Paulo (SP) - Brasil.

${ }^{3}$ Residente de Oftalmologia da Faculdade de Medicina do ABC - FMABC - Santo André (SP) - Brasil.

Endereço para correspondência: Adamo Lui Netto. Av. Indianópolis, 1485 - São Paulo (SP)

CEP 04063-002

E-mail: adamoluinetto@uo.com.br

\section{RESUMO}

Trauma ocular é causa importante de baixa de acuidade visual em todos os países do mundo. A integridade do bulbo ocular é primordial para recuperação visual nesses pacientes. Acidentes domésticos, automobilísticos, esportivos, além de queimaduras químicas e térmicas são as principais causas de trauma em nosso meio. O uso de lentes de contato é indicado para a reabilitação visual em casos de astigmatismos regulares ou irregulares de córnea, anisometropias, afacias, opacidades paracentrais superficiais ou profundas na córnea decorrentes do trauma ocular. As lentes de contato podem ser utilizadas no pós-trauma com finalidade terapêutica ou para correção visual. As lentes mais utilizadas para correção visual pós-trauma são as lentes de contato rígidas gás permeáveis, com alto coeficiente de permeabilidade. As lentes de contato gelatinosas podem ser usadas imediatamente após o trauma ocular com finalidade terapêutica e mais tardiamente para correção óptica em afacias e anisometropias traumáticas. A lente de contato é parte importante no tratamento tardio do trauma ocular, propiciando melhora significativa da acuidade visual na maioria dos casos.

Descritores: Traumatismos oculares/reabilitação; Lentes de contato; Acuidade visual

\section{Causas de trauma ocular}

Nos pacientes atendidos com trauma ocular, deve-se ter a preocupação para que os procedimentos a serem realizados mantenham a integridade do bulbo ocular proporcionando a recuperação da acuidade visual $^{(1)}$. Os traumas que resultam em perfurações como laceração corneal ou escleral, lesão do cristalino, perda de vítreo, entre outras e que requeiram sutura de córnea e esclera, facectomia, vitrectomia anterior ou posterior, deixam como seqüelas leucoma corneal, afacia, astigmatismo regular ou irregular. Estas condições são causas de redução da acuidade visual que não melhoram com óculos e muitas vezes são corrigidas com o uso de lentes de contato ${ }^{(1)}$.

A opacidade corneal devido ao trauma ocular é causa comum de morbidade ocular em todos os países do mundo ${ }^{(2)}$. A etiologia desses traumas oculares resulta de acidentes: de trabalho (no qual os projéteis são os mais comuns), automobilísticos, domésticos (principalmente em crianças causados por objetos afiados ou pontiagudos), queimaduras químicas ou térmicas, assaltos, atividades esportivas, energia eletromagnéticas e outros objetos cortantes implicados no trauma ocular ${ }^{(2)}$. Também o uso incorreto das lentes de contato são responsáveis por um dos três tipos mais freqüentes de trauma ocular. Ferimento metálico e acidente automobilístico são os outros dois ${ }^{(2-4)}$. 


\section{Prevalência do trauma ocular nos diversos países}

O trauma ocular é comum em todos os países do mundo. Nos EUA estima-se que ocorra aproximadamente 1 a 2,4 milhões de traumas oculares por ano. Na índia é a 5a causa mais comum de perda visual com prevalência de 7,3/1.000 habitantes e constitui $1,52 \%$ das causas de cegueira. No Brasil não existe estatística, mas avalia-se que ocorram de 500.000 a 600.000 traumas por ano com prevalência de $0,4 \%$ da população. Esta grande variação do número de casos reportados deve-se exclusivamente a diferentes categorias de traumas associados à tendência regional de fazer as notificações. Em 2003 foram registrados 390.180 acidentes sendo que 1997 correspondem aos traumatismos dos olhos e órbitas. As estatísticas oficiais do Ministério da Previdência e Assistência Social, que incluem somente trabalhadores sob regime da Consolidação das Leis do Trabalho e trabalhadores rurais, e os traumas oculares usualmente correspondem àqueles de maior gravidade, como os traumas abertos. Adicionalmente muitos traumas oculares, principalmente os menores, são tratados em clínicas particulares ou alguns não são tratados, e por isso não são notificados. Nos EUA, de 20.000 a 68.000 pacientes são hospitalizados por ano, com sérios traumas oculares que comprometem a visão (Figura 1). A admissão de pacientes do sexo masculino é 3 vezes mais freqüente que pacientes do sexo feminino, e adultos jovens são mais envolvidos do que adultos de mais idade ${ }^{(1-3,5-7)}$.

Em estudo retrospectivo, Cariello et al, analisando 273 prontuários de pacientes menores de 16 anos de idade, encontrou como causa mais freqüente de lesão ocular traumatismo com objetos externos como pedra, ferro ou madeira $(28,9 \%)$ e o local mais comum foi a própria casa $(53,1 \%)$. A acuidade visual inicial foi 0,5 em $63,4 \%$ dos traumas oculares fechados em $201(73,6 \%)$ acidentes. Setenta e seis pacientes $(27,8 \%)$ foram tratados com medicamentos e $48(17,6 \%)$ necessitaram de procedimentos cirúrgicos ${ }^{(8)}$.

Nos EUA a "National Society to Prevent Blindness" relatam que trauma ocular é a segunda maior causa de dano

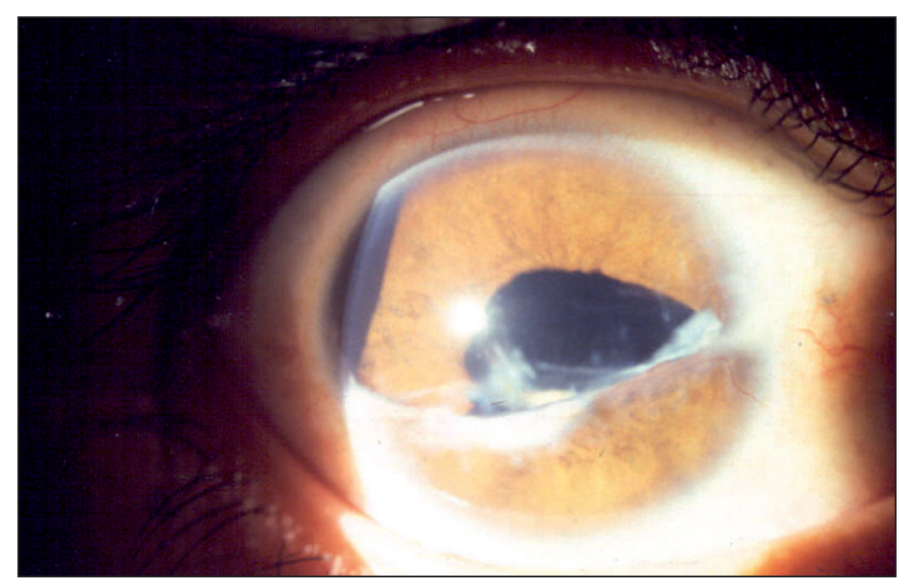

Figura 1 - Trauma ocular perfurante com perda do cristalino ocular na população, perdendo apenas para a catarata. Presume-se que em 1977, 938.000 pessoas tinham deficiência visual causada por trauma ocular ocorrido em alguma parte da vida, 7\% tinham perda grave da acuidade visual, 79\% eram cegos de um olho por trauma, sendo que 75\% dos casos relatados tinham idade inferior a 65 anos e $78 \%$ eram do sexo masculino ${ }^{(6)}$.

Deve-se medir a acuidade visual (AV) pós-trauma no momento da chegada do paciente ao PS, utilizando a tabela de Snellen. Quando for pior que 0,03 deve ser classificada em conta dedos, visão de vultos ou então em percepção e projeção luminosa ${ }^{(1-9)}$.

\section{Trauma ocular provocado por lentes de contato}

A lente de contato (LC) é uma forma muito utilizada para corrigir os erros de refração, propiciando melhora da acuidade visual em milhões de indivíduos no mundo. Calcula-se que hoje no Brasil existam 3.200.000 usuários de LC; nos EUA, 25.000.000 e na Europa, 15.000.000(10).

$\mathrm{O}$ médico deve estar consciente da alta prevalência de usuários de LC na população quando se deparar com paciente com trauma na cabeça ou ferimento ocular, que é mais comum em adultos jovens, grupo de maior prevalência do uso de LC. Os traumas podem ocorrer em usuários de LC, mas também podem ser a causa do ferimento ${ }^{(10)}$.

As lesões oculares provocadas pela LC incluem: abrasão corneal direta ou indiretamente causada pela lente, material sob a LC ou produtos químicos para limpeza e desinfecção que causam queimaduras químicas, abrasão de córnea na inserção ou remoção das LC. Úlceras corneais em usuários de LC podem provocar sérios danos na A.V. e na integridade do bulbo ocular, inclusive com perfuração, necessitando transplante de córnea para recuperação do olho e reabilitação visual $^{(10-11)}$.

\section{Indicações de lente de contato pós-trauma ocular}

As principais indicações de lente de contato pós-trauma ocular são quando ocorrem: anisometropias, afacias, astigmatismos regulares ou irregulares de córnea, opacidades nebulares ou nébulo-maculares na córnea, que são opacidades superficiais finas, limitadas às camadas subepiteliais ou estromais anteriores e leucomas corneais paracentrais ao eixo visual. A opacidade fina regular difusa, envolvendo a área pupilar interfere mais com a visão que a lesão cicatricial densa localizada fora do eixo visual. Estas opacidades refratam luz irregularmente e borram a imagem retínica formada por raios refratados de maneira irregular ${ }^{(11-12)}$.

A obscuridade e imprecisão causada pelo astigmatismo irregular das opacidades nebulares e nébulo-maculares são difíceis de corrigir com lentes oftálmicas esféricas, cilíndricas e esféro-cilíndricas, pois estas não corrigem as irregularidades da superfície corneal. Lentes de contato rígidas gás permeáveis (LC-RGP) ou transplante de córnea são outras opções. Devido às complicações inerentes dos transplantes 
de córnea esta proposição é a menos viável. Lentes RGP melhoram a acuidade visual encobrindo o astigmatismo irregular nas opacidades corneais ${ }^{(11-12)}$

Nos casos com lesões mais densas, que provocam leucoma corneal nas regiões central e paracentral do eixo pupilar, as LC-RGP devem ser testadas para verificar a possibilidade de reabilitação visual nestes olhos. Em casos de lesões mais profundas como as que provocam cicatrizes córneo-irídicas localizadas fora do eixo visual, a reabilitação da visão será mais factível do que se localizada na zona óptica. Além disso, as LC estão indicadas em pacientes com traumas oculares, nas anormalidades írido-pupilares, nos olhos desfigurados ou deformados, na prevenção da ambliopia e no restabelecimento do olho traumatizado ${ }^{(11-12)}$.

Pacientes com ceratite herpética, olho seco, anormalidades palpebrais, alterações do segmento posterior do olho e ambliopia devem ser muito bem avaliados antes de serem excluídos ${ }^{(11-12)}$.

\section{Qual o melhor momento para adaptação de lente de contato?}

As lentes de contato são parte importante no tratamento tardio do trauma ocular, proporcionando melhora significativa da acuidade visual na maioria dos $\operatorname{casos}^{(11-12)}$. O tempo de espera para adaptação das LC pós-trauma requer que seja realizado um exame oftalmológico criterioso para avaliar cada indivíduo. Acuidade visual sem correção, assim como a melhor acuidade visual com óculos deve ser anotada. Exame oftalmológico detalhado deve ser realizado, incluindo pálpebras e anexos oculares. O menisco lacrimal deve ser examinado realizando o teste do tempo de ruptura do menisco lacrimal (Break-up time - BUT), assim como o teste de Schirmer. A medida do tamanho da opacidade corneal deve ser anotada, bem como a sua relação com a zona pupilar. Meticuloso exame ocular deve ser feito à biomicroscopia. Avaliação fundoscópica, tonometria e ceratometria e/ou videoceratoscopia devem ser realizados ${ }^{(11-13)}$

Se o trauma provocar a perda do cristalino e não levar cicatrizes na região do eixo visual pode-se adaptar LCG inclusive de imediato, não necessitando aguardar a retirada dos

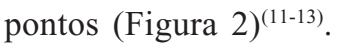

Lentes RGP devem ser adaptadas após a retirada dos pontos. Em alguns casos para recuperar a visão mais precocemente, lentes RGP podem ser adaptadas antes da retirada dos pontos, mas o paciente deve ser avisado dos riscos e das complicações. Neste caso, deverá procurar o oftalmologista toda vez que ocorrer piora da acuidade visual, ou no caso de se instalar um processo inflamatório que interfira no conforto do uso da $\mathrm{LC}^{(10-13)}$.

\section{Qual a lente de contato mais recomendável para adaptar pós-trauma ocular?}

As lentes RGP com elevado Dk são as mais indicadas por propiciarem a melhor adaptação com excelente transmissibilidade de oxigênio, movimentando-se bem na córnea, promo-

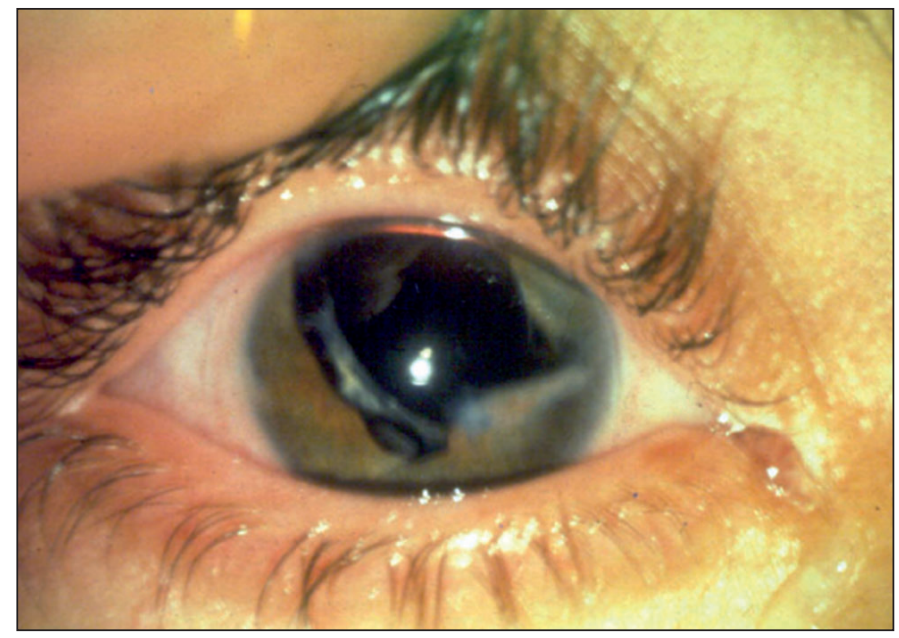

Figura 2 - Trauma ocular perfurante com perda do cristalino e zona óptica livre, adaptado com LCG

vendo boa troca de filme lacrimal e melhor acuidade visual do que a conseguida com os óculos ou $\mathrm{LCG}^{(10-13)}$. A preferência por LC RGP é mostrada em pacientes que tentaram a adaptação de LCG, que embora proporcionem maior conforto, só tiveram acentuada melhora da acuidade visual com a adaptação das $\mathrm{RGP}^{(1)}$.

\section{Critérios de escolha entre lentes de contato LCG e RGP}

A adaptação de LCG pós-trauma ocular é indicada quando existe ametropia esférica especialmente na afacia traumática e quando os pontos ainda não foram retirados. É indicado também quando as cicatrizes corneais estão fora da zona óptica. Após a retirada dos pontos as lentes RGP são indicadas, pois previnem complicações como reações inflamatórias e neovascularização corneal ${ }^{(10-12)}$.

A LCG deve ser de alto Dk, de uso prolongado (UP), mas a sua remoção deve ser feita diariamente. Após a retirada dos pontos, adaptar $\mathrm{RGP}^{(10-12)}$

\section{Indicação de LCG após trauma ocular}

São as lentes de UP de alto Dk ou as lentes descartáveis, mas que devem ser removidas diariamente. Quando o trauma ocular provoca afacia, a LCG pode oferecer boa acuidade visual mesmo com astigmatismo regular ou irregular, pois estas lentes são mais espessas no centro propiciando boa correção visual ${ }^{(10-12)}$.

\section{Indicação das LC-RGP após trauma ocular}

São as lentes de alto Dk de preferência as de Dk 92, 100 ou mais por propiciarem melhor transmissibilidade do oxigênio. Entretanto por estas lentes serem mais flexíveis, podem não corrigir graus maiores de astigmatismos regulares ou irregulares. Nestes casos devemos adaptar lentes menos flexíveis com menor Dk (36, 56 e outras), pois podem melhorar a qualidade visual $^{(12-13)}$. 


\section{Função da LC para a reabilitação visual pós-trauma ocular com perda do cristalino}

A afacia é resultado de um grave trauma com penetração ocular. O cristalino pode ser perfurado, subluxado ou luxado primariamente, sendo necessário removê-lo durante o processo restaurador; ou pode ficar opacificado mais tardiamente requerendo remoção cirúrgica e implante de lente intra-ocular (LIO). Se a anatomia do olho foi gravemente alterada pelo trauma e o implante da LIO não pode ser realizado, o olho ficará afácico. Para crianças em idade ambliogênica a afacia requer cuidados especiais. Combinado com laceração corneal, o manejo da parte óptica e a ambliopia estabelecem significantes alterações. Neste caso as lentes são indicadas quando existe afacia mono-ocular, o que provoca acentuada anisometropia $^{(12-13)}$.

Em caso de perfuração única o médico poderá optar por LCG ou LC-RGP, dependendo do total do astigmatismo corneal e refrativo. A LCG é mais tolerada fisicamente pelo conforto e serve de proteção para o olho traumatizado. No caso de miopia, hipermetropia ou de astigmatismo residual moderados, esta correção deverá ser feita pelos óculos ${ }^{(12-13)}$.

A LC-RGP deve ser indicada quando o objetivo principal é melhorar a visão em caso de astigmatismo irregular. O astigmatismo irregular em diversas formas é comum após trauma ocular, principalmente na fase inicial. Se o astigmatismo permanecer, a localização e o grau de irregularidade são parâmetros fundamentais para determinar qual a melhor correção. Astigmatismo irregular ocorre em: queimaduras químicas, abrasão corneal, trauma não penetrante por objetos rombos, e alguns tipos de laceração. Alguns casos mais superficiais melhoram com o tempo; outros requerem correção com $\mathrm{LC}^{(12-13)}$.

Trauma grosseiro penetrante ou não penetrante, qualquer que seja a etiologia, comumente leva a um transtorno de uma grande porção do segmento anterior do olho, incluindo íris e cristalino. Injúria da íris pode provocar problemas ópticos e desfiguração cosmética ${ }^{(12-13)}$.

Quando o dano da íris provoca também danos visuais, estes devem ser corrigidos com LCG ou LC-RGP, dependendo se tem astigmatismo regular ou irregular que prejudica a correção óptica com óculos, para proporcionar melhor acuidade visual ${ }^{(12-13)}$.

Entretanto o trauma pode provocar deformação da íris através de lesão no nervo ( $3^{\circ}$ par craniano), causando midríase paralítica por lesão do esfíncter muscular (Figura 3). Pode provocar ruptura do esfíncter muscular ou iridectomia traumática, ou ainda perda por secção parcial ou total no processo de reparação cirúrgica do trauma. A restauração da aparência física é tão importante quanto o restabelecimento da função visual. Pupilas discóricas ou policóricas, além dos problemas cosméticos, provocam também problemas ópticos. É mais comum em pacientes afácicos ou pseudo-fácicos, mas podem estar presentes em pacientes fácicos. Imagens múltiplas e fotofobia estão associadas a estes problemas. Nestes casos, as LC podem servir como novo diafragma óptico criando uma pupila artificial, limitando a porção de entrada da luz ou imagem para o espaço visual determinado pela $\mathrm{LC}^{(12-13)}$.

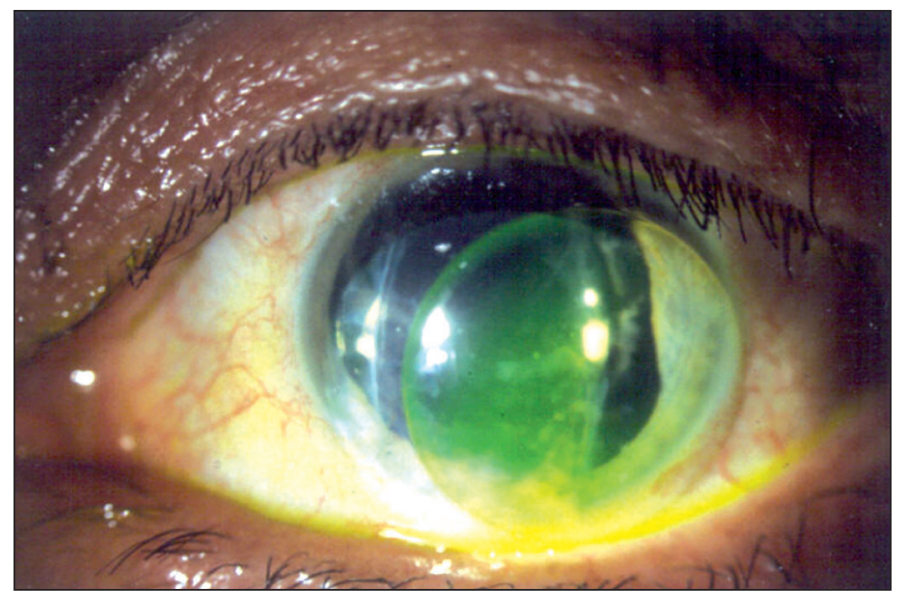

Figura 3 - Midríase paralítica pós-trauma, ideal para RGP grande $(10,2 \mathrm{~mm})$ ou LCG

O trauma pode desfigurar o olho, por lesões que provocam opacidades corneais, danos na íris, cataratas, lesões esclerais, conjuntivais e palpebrais. Lentes cosméticas, protéticas ou próteses esclerais podem ser adaptadas dependendo da extensão das lesões, provocadas pelo trauma ocular. Lentes terapêuticas são indicadas principalmente em casos que necessitam de proteção do epitélio corneal contra o trauma provocado pelas pálpebras, ou em caso de abrasão ou laceração superficial da córnea, pequenas lesões perfurantes ou descemetocele. Prefere-se usar LCG descartável. LC de colágeno são pouco usadas por se desintegrarem rapidamente. As lentes terapêuticas devem ser usadas para a correção óptica quando existe indicação para sua adaptação( ${ }^{(12-13)}$.

\section{Qual o melhor momento para adaptar LC pós-trauma?}

É fundamental na adaptação de LC pós-trauma, fazermos um histórico completo do paciente. Devemos averiguar se o paciente teve experiências anteriores com correções ópticas e se teve problemas com óculos ou LC. Nestes casos deve-se valorizar os dados do paciente e avaliar a sua expectativa quanto ao resultado a ser obtido com a adaptação da $\mathrm{LC}^{(11-13)}$.

Verificar a natureza do trauma ocular. Examinar o olho, anexos oculares, face, cabeça, sistema nervoso, mãos e braços, para avaliar sua capacidade de inserir e remover a $\mathrm{LC}^{(10-13)}$.

Pesquisar problemas de alergia, diabetes, anormalidade neurológica ou músculo-esquelético afetando a tonicidade da musculatura palpebral, alterando o piscar. Alergia aos produtos de conservação, limpeza e assepsia das LC, é um dos problemas mais comuns. $\mathrm{O}$ grau de motivação, que deve ser de moderado a alto, é de extrema importância para manter o indivíduo usando LC e aceitar a superação inicial dos problemas adaptativos, mantendo o indivíduo em condições de sucesso para a reabilitação visual. Deixá-lo consciente dos problemas a serem superados no início e instruí-lo da importância de seguir as instruções de uso das LC para evitar complicações ${ }^{(12-13)}$.

Exame físico detalhado de avaliação das estruturas afetadas pelo trauma, inspeção do sistema estrutural e funcional, déficit 
anatômico e neurológico, inspeção da anatomia ocular, superfície corneal, medida da acuidade visual, refração, motilidade ocular extrínseca e a integridade do sistema lacrimal ${ }^{(10-12)}$.

\section{Avaliação da acuidade visual e a refração no olho com trauma ocular}

Acuidade visual sem correção e com correção devem ser medidas, estas servem de referências para futuras comparações do quanto a visão melhorou desde os testes iniciais com óculos e LC até a melhora da visão final com LC. Estas comparações das medidas da acuidade visual pré e pós adaptação servem para motivar o paciente a se adaptar com as $\mathrm{LC}^{(12)}$.

A medida da refração é igualmente importante como a medida da acuidade visual. Em crianças, jovens e adultos fácicos, a cicloplegia é indicada. Se a superfície corneal é irregular LCRGP deve ser indicada para realizar a refração ${ }^{(12)}$.

\section{Alterações na topografia corneal que ocorrem após trauma ocular}

A laceração traumática corneal pode se associar com significante astigmatismo regular ou irregular, mesmo após meticuloso procedimento cirúrgico. O conhecimento da topografia corneal pós-trauma é essencial para a escolha da LCG ou LC-RGP(11,14-15).

Estudando as mudanças na topografia corneal após incisão cirúrgica e laceração traumática encontra-se ${ }^{(11,14-15)}$ :

- A córnea normal aplana sob uma incisão ou laceração vertical;

- A incisão ou laceração corneal aplana a córnea adjacente e a 90 graus continuadamente;

- O efeito de aplanamento corneal aumenta quando a incisão ou laceração se aproximam do eixo visual;

- A córnea se aplana diretamente sob uma incisão ou laceração suturada;

- A córnea encurva adjacente à sutura límbica apertada e encurva nos 180 graus contínuos e se aplana nos 90 graus opostos;

- A córnea se aplana sob a ressecção da margem da laceração;

- A córnea aplana anteriormente à margem da ressecção;

- A remoção de tecido cirúrgico ou traumático, produz aplanamento corneal no local do tecido removido;

- Quando há laceração corneal não perfurante, ocorre aplanamento acentuado no local da laceração. Este aplanamento é secundário à margem da ferida e a subseqüente adição de tecido, iniciando com a formação de um tampão epitelial. Este tampão epitelial é eventualmente empurrado pelo colágeno estromal, que é tecido cicatricial, com adição de tecido, criando aplanamento na córnea adjacente assim como aplanamento a 90 graus do local da laceração ${ }^{(11,14-15)}$.

A laceração que penetra na câmara anterior resulta no acentuado aplanamento corneal devido ao movimento anterior do estroma da córnea edemaciada e da deiscência da ferida ${ }^{(11,14-15)}$.

Laceração corneal que requer sutura resultará em aplanamento corneal devido à compressão da lesão que ocorre para fechar a laceração. A sutura de compressão aplana a córnea diretamente sob a sutura, com encurvamento induzido adjacente à sutura límbica apertada, encurvando a córnea a 180 graus. A córnea aplana a 90 graus do local da laceração, com sutura límbica apertada ${ }^{(11,14-15)}$.

A córnea pós-trauma freqüentemente mantém-se esférica ou quase esférica na periferia. Isto é fundamental para a adaptação da LC-RGP que irá tocar a média-periferia da córnea, aproximadamente a $4 \mathrm{~mm}$ do centro geométrico. Estudos mostram que grande parte dos traumas oculares ocorre abaixo da linha média da córnea. Manter a topografia corneal superior normal no pós-trauma é a melhor condição no sucesso da adaptação de LC-RGP. Isto permite que a LC mantenha uma grande área de alinhamento superior, permitindo que a pálpebra superior ajude no posicionamento e retenção da $\mathrm{LC}^{(11,14-15)}$.

A córnea traumatizada na região inferior pode aplanar ou encurvar secundariamente à sutura ou contração da cicatriz. Esta elevação inferior cria pouco ou nenhuma dificuldade na reabilitação visual com LC-RGP. A grande dificuldade para adaptar LC no pós-trauma é quando a região lesada é a superior, pois adaptar LC sobre a grande área lesada, manter o alinhamento da LC sobre a córnea é muito difícil ${ }^{(11,14-15)}$.

É importante lembrar que o aplanamento corneal e astigmatismo induzido são tanto maiores quanto mais a laceração se aproxima da região central da córnea. Entretanto as medidas ceratométricas ou videoceratoscópicas podem levar a erro se usadas como parâmetro para teste das LC pós-trauma. Os testes devem ser realizados para que a lente definitiva se alinhe o mais normal na córnea superior o que é mais fácil se a córnea tiver sido pouco lesada nesta região $0^{(11,14-15)}$.

Em resumo, o maior efeito da laceração da córnea sobre a visão advém da irregularidade na superfície. A cicatriz resultante pode ser importante para a visão se ela se localizar no eixo visual, principalmente se ocluir a maior parte deste espaço (Figura 4). Cicatrizes fora do eixo visual afetam a visão por alterar a topografia que se estende até o centro visual provocando astigmatismo irregular ${ }^{(11,14-15)}$.

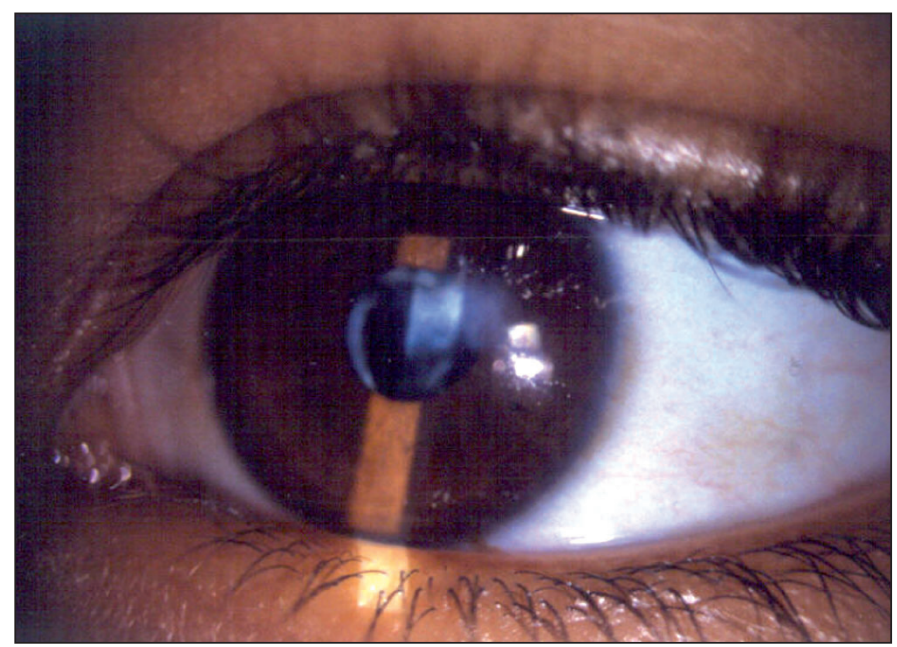

Figura 4 - Trauma afetando o eixo visual 


\section{A importância da verificação do filme lacrimal na adaptação da LC pós-trauma}

A qualidade do filme lacrimal e a quantidade volumétrica são de igual ou de maior importância na adaptação das LC no olho pós-trauma como o são em todos pacientes adaptados com LC ${ }^{(10-11)}$.

A insuficiência lacrimal em olhos com topografia irregular acentua os problemas epiteliais que as LC induzem. O teste de ruptura do filme lacrimal (BUT) indica significante disfunção da glândula de Meibomius, se o intervalo de ruptura for inferior a 10 segundos ${ }^{(10-11)}$.

Se a desepitelização corneal é acelerada, o que contribui para aumentar o número de células sob a LC, o problema de descamação corneal se acentua, aumentando as complicações e piorando a tolerância à LC. O teste de Schirmer tem valor limitado mas pode ser útil se outros testes forem inconclusivos. Este teste em olhos traumatizados pode levar ao erro ou a um falso negativo ${ }^{(10-11)}$.

\section{Seleção da LC para adaptação no pós-trauma ocular}

A lente de contato RGP esférica é a primeira escolha para pacientes com laceração corneal e representa a referência na qual vão ser comparados os processos de reabilitação visual. A lente rígida corrige as deformidades da córnea corrigindo o astigmatismo regular ou irregular ${ }^{(10-11)}$.

Não existe regra fixa estabelecida para adaptar LC-RGP em pacientes com trauma ocular, mas o teste inicial deve ser baseado na videoceratoscopia. Mesmo assim a relação entre lente e córnea será baseada na imagem encontrada na biomicroscopia (Figuras 5 e 6). Normalmente a curva base da lente é selecionada baseando-se na zona média periférica da córnea que deverá ser aproximadamente $3 \mathrm{~mm}$ superior ao eixo visual. Para o primeiro teste, seleciona-se a curva base da lente mais plana que $\mathrm{K}$; para astigmatismo menor que 1D adapta-se em K; astigmatismo entre $1 \mathrm{D}$ e $2 \mathrm{D}$ soma-se $0,50 \mathrm{em}$ $\mathrm{K}$; e astigmatismo maior que $2 \mathrm{D}$ soma-se $25 \%$ em $\mathrm{K}^{(10-11,14)}$.

Para manter a estabilidade da LC, o diâmetro deverá ser grande podendo variar de 9,0 a $11,0 \mathrm{~mm}$, porém o mais utilizado é o de $9,6 \mathrm{~mm}$ a 10,2 $\mathrm{mm}$ e estes também são indicados para pupilas grandes e irregulares. Para pupilas menores que 4,0 mm e regulares, são indicadas lentes com diâmetro menor ou igual a $9,0 \mathrm{~mm}$, desde que mantenham boa centralização. A espessura central das lentes varia de 0,12 a $0,15 \mathrm{~mm}$ em correções negativas e em olhos fácicos. Em olhos afácicos, nos quais a dioptria positiva é alta (em torno de $+15,00 \mathrm{D}$ ), a espessura central será de aproximadamente $0,25 \mathrm{~mm}$. O material mais utilizado é o polifluorosiliconemetacrilato e o coeficiente de permeabilidade preferido é o Dk 96, com espessura menor o que proporciona maior troca de oxigênio. Entretanto, LC com Dk 71, 58 e de siliconemetacrilato Dk 58 e 36, por serem menos flexíveis, também poderão ser utilizadas para corrigir irregularidades corneais mais acentuadas. Lentes com Dk 100 ou mais podem ser utilizadas em olhos com pouco astigmatismo regular ou irregular ${ }^{(10-11,14)}$.

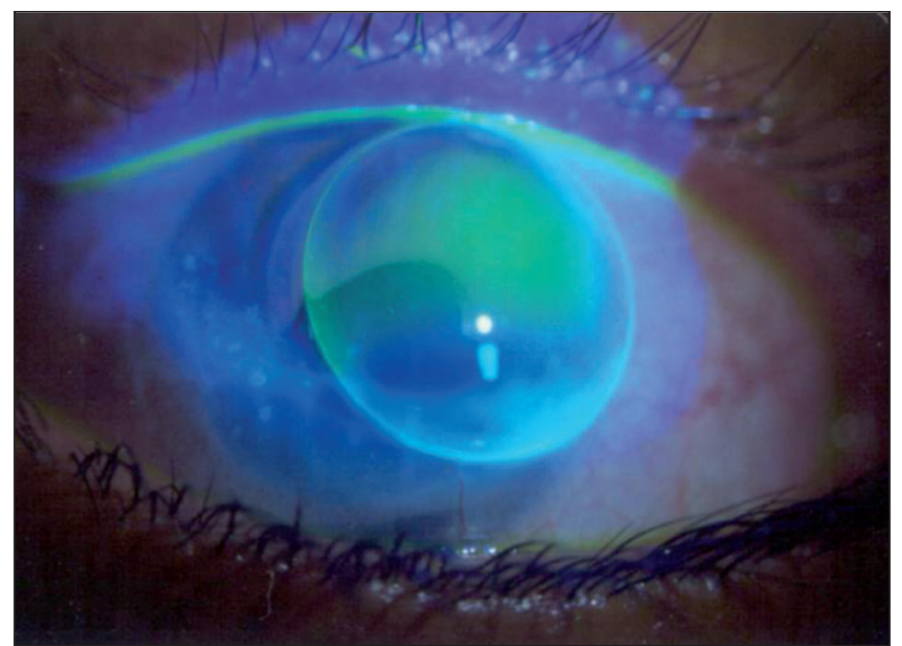

Figura 5 - Biomicroscopia com fluoresceína, com toque superior e acúmulo central

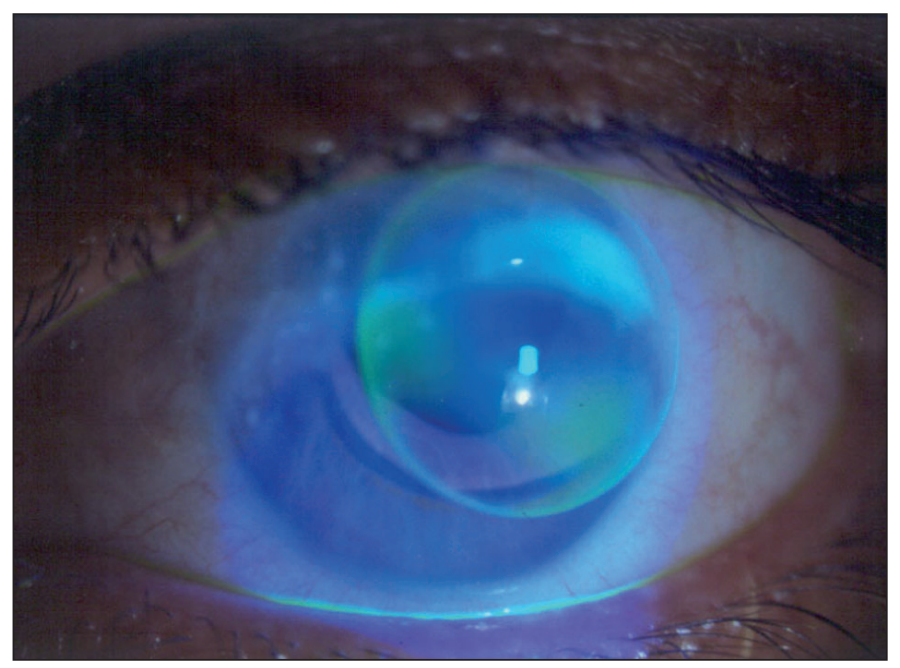

Figura 6 - Biomicroscopia com fluoresceína, com toque lateral e acúmulo marginal (Boa adaptação)

A LC deverá ter boa centralização e movimentação e o filme lacrimal entre a lente e a córnea, examinado à biomicroscopia com fluoresceína, deverá ser fino e uniforme, com boa troca de fluoresceína a cada piscada (Figura 7). O poder dióptrico da lente final será obtido fazendo sobre-refração na LC de prova no teste sobre a córnea traumatizada ${ }^{(11)}$.

\section{Regras básicas para adaptação de RGP}

O desenho da lente deverá ser o que melhor se alinhar com a área da córnea menos afetada pelo trauma (usualmente superior, podendo ser nasal ou temporal $)^{(11-12)}$.

- Adaptar a LC sobre a área mais apertada da córnea seja a induzida pela cicatriz ou pela sutura.

- Usar diâmetro grande para posicioná-la melhor sob a pálpebra superior e permitir melhor posicionamento na área irregular e/ou no astigmatismo corneal irregular. 
- Lentes de contato RGP tórica de face posterior cujo desenho não deve ser baseado na ceratometria central.

A toricidade corneal será tanto maior quanto mais a laceração se aproxima do centro visual. A córnea periférica e a média periferia mantêm a forma próximo do esférico ${ }^{(11-12)}$.

\section{Quando adaptar LCG pós-trauma corneal}

A reabilitação com LCG esférica ou tórica só é possível quando a córnea pós-trauma apresentar um mínimo de cicatriz irregular. A ceratometria e a videoceratoscopia fornecem dados significantes relativos ao grau de irregularidade do astigmatismo corneal central. Se a imagem refletida é regular e livre de distorções, a refração mais precisa será realizada. Se a refração for estável após duas ou três medidas em semanas subseqüentes a adaptação da LC pode ser iniciada ${ }^{(10-11)}$.

Se o astigmatismo corneal central estiver presente, LCG esférica pode ser adaptada, e o astigmatismo residual será corrigido com óculos. A LCG adaptada deverá ter posição estável e movimento adequado. O paciente será orientado a usar LCG apenas em uso diário ${ }^{(10-11)}$.

Uma cuidadosa sobre-refração (isto é, refração com LC) deverá ser realizada após uma ou duas semanas para determinar o astigmatismo residual. Se este for bem tolerado, nova correção não deverá ser prescrita. Entretanto, se mal tolerado, prescrição de óculos sobre a LCG ou caso o paciente não deseje correção com óculos, a LCG tórica deverá ser prescrita desde que a córnea permita a sua adaptação. Antes de adaptar LCG tórica verificar se a topografia e a refração estão estáveis através de medidas seriadas semanais ou em exames de rotina ${ }^{(10-11)}$.

Fazer testes com LCG tórica para determinar o eixo do cilindro e o poder dióptrico deverá ser calculado com base na correção com óculos e com a correção esferocilíndricas sobre a lente do teste ${ }^{(10-11)}$.

Nas consultas de controle, neovascularização poderá ser verificada nas lacerações translímbicas. Estas não impedem

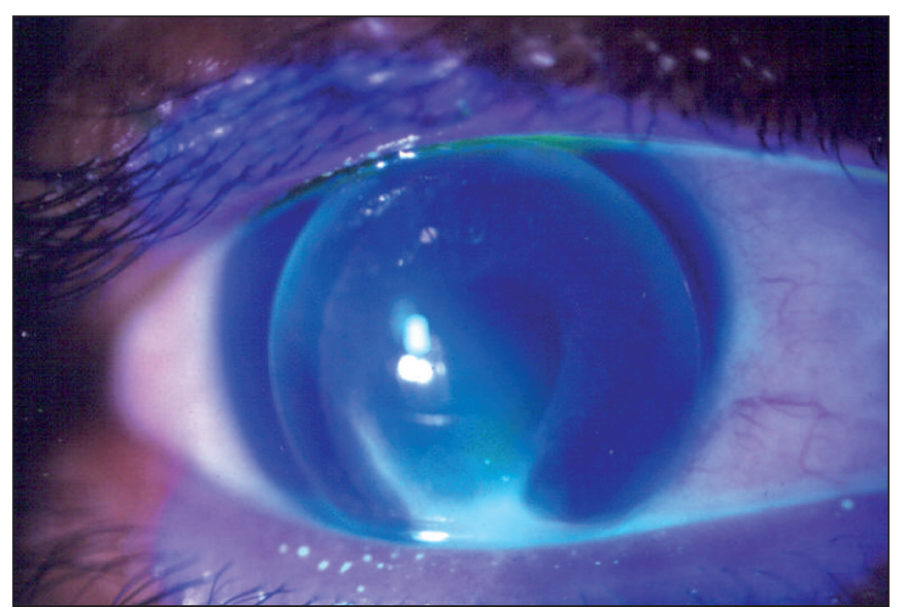

Figura 7 - Biomicroscopia de LC pós-trauma com distribuição uniforme de fluoresceína que o paciente continue a usar LCG, mas indica que hipóxia ou trauma mecânico estão ocorrendo. Para minimizar os problemas, aplanar a LC, diminuir o seu tempo de uso, controlar a sua desidratação usando soluções lubrificantes livres de preservantes ou trocar as LCG por materiais com alto Dk a fim de aumentar a permeabilidade do oxigênio. Se não houver melhora da vascularização LC-RGP deverá ser indicada ${ }^{(10-11)}$.

Quais são as demais alternativas para adaptação de LC pós-trauma corneal

As alternativas para LC-RGP e LCG, para adaptação póstrauma de córnea são: lentes em "piggyback" e lente SoftPerm $^{\circledR(11-13)}$.

A lente em "piggyback" que é a lente RGP adaptada sobre a LCG, está indicada em pacientes com intolerância intermitente à LC-RGP, e que necessitam usar lente rígida devido ao significante astigmatismo central irregular ${ }^{(11-13)}$.

A adaptação deve ser feita da seguinte maneira:

a) adapte LCG de alto $\mathrm{Dk} / \mathrm{L}$, de poder dióptrico plano e aguarde $30 \mathrm{~min}$;

b) faça ceratometria ou videoceratoscopia sobre a superfície anterior da LCG;

c) adapte a LC-RGP sobre a LCG como se estivesse adaptando sobre a córnea normal;

d) avalie a relação lente-lente, à biomicroscopia e sendo necessário usar fluoresceína de alto peso molecular e fazer os ajustes;

e) quando a LC-RGP estiver adaptada, proceder à refração sobre as duas lentes;

f) o poder dióptrico é calculado para a RGP e deve ser pedida lente de alto $\mathrm{Dk} / \mathrm{L}$.

As complicações são relativas a respostas fisiológicas adversas provocando hipóxia e neovascularização no local da lesão cicatricial que podem ser minimizados escolhendo os parâmetros apropriados, permitindo que ambas as lentes tenham alguma mobilidade durante o piscar ${ }^{(11-13)}$.

$\mathrm{O}$ uso destas lentes deve ser ocasional ou com limitação do número de horas diárias, para evitar complicações ${ }^{(11-13)}$.

As lentes SoftPerm ${ }^{\circledR}$ são fabricadas pelo Pilkington Barnes-Hind (PBH), que combina na periferia LC hidrofílica e no centro a lente de butil-estireno e silicone-acrilato, para corrigir os erros refrativos atípicos ${ }^{(11)}$.

O diâmetro total da SoftPerm ${ }^{\circledR}$ é de $14,5 \mathrm{~mm}$, sendo que o centro rígido tem $8,0 \mathrm{~mm}$ de diâmetro com $7,0 \mathrm{~mm}$ de zona óptica. O conteúdo aquoso da LCH na periferia é de $25 \%$ e o Dk da lente é de $14 \times 10^{-11(11)}$.

O centro rígido de butil-estireno permite corrigir altos graus de astigmatismo regular e irregular presente na córnea pós-trauma. A margem gelatinosa proporciona a distribuição da LC sobre a córnea, limbo e esclera, a fim de posicionar a zona óptica diretamente sobre a pupila ${ }^{(11)}$.

Os problemas que ocorrem com a lente SoftPerm ${ }^{\circledR}$ são: aperto periférico com diminuição do movimento adequado; complicações fisiológicas devido à pequena mobilidade da LC, dificuldade de remover a $\mathrm{LC}^{(11)}$. 
Nos exames de controle da adaptação a LC deve ser examinada ao microscópio para verificar depósitos, rasgos e imperfeições. A zona de transição deve ser inspecionada ${ }^{(11)}$.

\section{Controle das $L C$ adaptadas pós-trauma ocular}

O controle de adaptação da LC pós-trauma ocular, deve ser realizado após dois a três dias de uso com o paciente usando suas lentes por quatro a seis horas. Avaliar a relação entre lente e córnea e a integridade do epitélio corneal, se a LC utilizada for a RGP. Se for LCG verificar a relação lente-córnea e, também, verificar na periferia límbica se a lente está muito apertada e se existe algum mecanismo de hipóxia presente. Em caso de alteração nova lente deverá ser adaptada ${ }^{(10-11)}$.

O controle deverá ser mensal no primeiro trimestre e após a cada semestre. Em todos os exames, verificar à biomicroscopia, se a córnea não tem alterações como: edema epitelial, descamação, ceratite, entre outros. Verificar se a LC tem lascas, rasgos ou arranhões. Fazer topografia de córnea para verificar se houve irregularidades em relação à topografia prévia da adaptação. Se houver qualquer dúvida a LC deverá ser retirada e examinada detalhadamente. Se houver necessidade deverá ser trocada ${ }^{(10-11)}$.

\section{Quais as complicações mais freqüentes das LC em olhos com trauma ocular}

As complicações mais freqüentes são:

- Edema epitelial;

- Infiltrados epiteliais;

- Ceratopatia pontilhada superficial;

- Edema estromal;

- Erosão da córnea;

- Neovascularização;

- Alterações ceratométricas e refracionais ${ }^{(10-11)}$.

\section{Avaliação dos resultados visuais das LC adaptadas pós-trauma ocular}

Os estudos mostram que existe melhora da acuidade visual em relação aos óculos tanto das lentes RGP e LCG. Entretanto, as LC-RGP, por corrigir melhor os astigmatismos tanto regular como irregular, mostram-se as mais indicadas para melhorar a acuidade visual ${ }^{(12)}$.

A acuidade visual deve ser avaliada com a tabela de Snellen, colocada a 6 m de distância, sem correção e, após, com os óculos e com lente de contato, para avaliar quanto foi o ganho visual com as lentes de contato ${ }^{(12)}$.

Testes de sensibilidade de contraste podem ser realizados para revelar perdas não detectadas na aferição da acuidade visual ${ }^{(12)}$.

Teste de estereopsia deve ser realizado quando a acuidade visual no olho traumatizado for $\geq 0,5^{(12)}$. Deverá ser repetido em 3 meses se houver melhora da acuidade visual com o uso da $\mathrm{LC}^{(12)}$.

\section{CONCLUSÕES}

Após trauma ocular, em olhos que apresentam cicatriz corneal, com astigmatismo regular e/ou irregular, as LC RGP são mais indicadas por propiciarem melhor correção visual. As
LC-RGP deverão ser de alto coeficiente de permeabilidade, mas devem ser removidas diariamente, isto é, deverão ser LC de uso diário com troca anual. A motivação do paciente é imprescindível para o sucesso da adaptação, devendo ser orientado sobre os benefícios do uso da LC para melhora da sua acuidade visual.

A reparação cirúrgica das lacerações corneais deve ser feita visando reduzir as cicatrizes para propiciar a adaptação precoce da LC para restabelecer a acuidade visual. Em crianças adaptar LC o mais precoce possível, mesmo antes da retirada dos pontos de sutura, pois o problema da ambliopia é mais eminente.

\section{ABSTRACT}

Ocular trauma is an important cause of visual acuity loss worldwide. Visual recovery is related to anatomical integrity. The main causes of trauma are domestic and automobilist accidents, sports practice and chemical or thermic burns. Contact lens is indicated for visual rehabilitation in cases of corneal regular and irregular astigmatisms, anisometropic and aphakic patients and in cases of deep or superficial corneal opacities that do not affect the visual axis. Contact lens can be used in the post- trauma period for therapeutic and optical purposes. Rigid gas permeable contact lens, with a high permeability index, is the most used for optical purpose. Soft contact lens can be used immediately after trauma as therapy or later for optical correction in aphakic and anisometropic patients. In most cases contact lens is an important part of trauma treatment improving visual acuity in the majority of cases.

Keywords: Eye injuries/rehabilitation; Contact lens; Visual acuity

\section{REFERÊNCIAS}

1. Alvim HS, Costa LT, Tárcia RA, Sá Filho LF. Adaptação de lentes de contato pós-trauma ocular. Arq Bras Oftalmol. 2003;66(4):477-80.

2. Netto LA. Adaptação de lente de contato (LC) pós-trauma ocular. In: CoralGhanem C, Kara José N. Lentes de contato na clinica oftalmológica. Rio de Janeiro: Cultura Médica; 2005. p.101-10.

3. Kara José N, Alves MR, Bonanomi MT, Sousa Júnior NA. Ferimento perfurante de globo ocular na infância. Rev Bras Oftalmol. 1981;40(3):243-54.

4. McMahon TT. Ocular trauma. In: Bennett E, Weissman BA. Clinical contact lens practice. Lippincott: Philadelphia; 1993. p.1-10.

5. Alves MR, Kara José N, Prado Jr J, Usuba FS, Onclinx TM, Marantes CR. Ferimento perfurante ocular: 400 casos admitidos na clínica oftalmológica do Hospital das Clínicas da Faculdade de Medicina da Universidade de São Paulo. Arq Bras Oftalmol. 1995;58(5):342-5.

6. Navon SE. Topography after repair of full-thickness corneal laceration. J Cataract Refract Surg. 1997;23(4):495-501.

7. Gerente VM, Melo GB, Regatieri CVS, Alvarenga LS, Martins EN. Trauma ocupacional por corpo estranho corneano superficial. Arq Bras Oftalmol. 2008;71(2):149-52.

8. Cariello AJ, Moraes NS, Mitne S, Oita CS, Fontes BM, Melo Júnior LA Achados epidemiológicos do trauma ocular na infância. Arq Bras Oftalmol. 2007;70(2):271-5.

9. Aragaki GN, Inada ET, Teixeira MF, Almeida Júnior GC, Kashiwabuchi LK. Estudo epidemiológico dos traumas oculares graves em um Hospital Universitário de São José do Rio Preto - SP. Arq Bras Oftalmol. 2003;66 (4):473-6. 
10. Moreira SBM, Moreira H. Lentes de contato. $2 \underline{a}$ ed. Rio de Janeiro: Cultura Médica; 2004. p.307-9.

11. Stein HA, Freeman MF, Stein RM, Maund LD. Residents contact lens curriculum manual. $2^{\text {nd }}$ ed. New York: CLAO; 1999. p.143-59.

12. Titiyal J, Das A, Dada VK, Tandon R, Ray M, Vajpayee RB. Visual performance of rigid gas permeable contact lenses in patients with corneal opacity. CLAO J. 2001;27(3):163-5.
13. Kanpolat A, Ciftçi OU. The use of rigid gas permeable contact lenses in scarred corneas. CLAO J. 1995; 21(1):64-6.

14. Jankov M, Reggi JRA, Lui Netto A, Naufal SC, Dantas PEC, Dantas MCN. Topografia da córnea após perfuração corneal. Arq Bras Oftalmol. 2002;65:183-91.

15. Netto LA, Ritchey E. Contact lens fitting after ocular trauma. In: Mannis MJ, Zadnik K, Coral-Ghanem C, Kara-José N. Contact lenses in ophthalmic practice. New York: Springer; 2003. p.168-80. 